\title{
Investigation of cure induced shrinkage in unreinforced epoxy resin
}

\author{
Mauro Zarrelli*, Alexandros A Skordos and Ivana K Partridge \\ Advanced Materials Dept, Cranfield University, Cranfield, Bedford, MK43 0AL, UK
}

\begin{abstract}
Changes in volume and thermal expansion coefficient were investigated during the cure of a high temperature curing epoxy resin containing a thermoplastic modifier. The measurements were carried out using a combination of standard and novel thermoanalytical techniques. It is shown that the chemical shrinkage of the curing resin is a linear function of the degree of cure, whereas the coefficient of thermal expansion depends on the temperature and on the degree of cure. This experimental information is translated to an incremental model that simulates the volumetric changes occurring as the resin follows a programmed thermal profile. Such a model can serve as a density sub-model in simulating heat transfer or residual stress development in composites during the manufacturing process.
\end{abstract}

\section{BACKGROUND}

Chemical reactions taking place during the cure of a thermosetting resin determine the route by which the structure of the material changes from a liquid to a cross-linked solid. At any point in the cure this structure determines the chemical, thermal and mechanical properties associated with the given instantaneous degree of cure ${ }^{1}$. The formation of chemical crosslinks leads to a volumetric shrinkage. This cure induced shrinkage in thermosetting resins and their continuous fibre reinforced composites remains a poorly understood and only partially quantified feature of the processing operation, affecting issues such as warpage and residual internal stresses in composite structures.

The residual stresses are a consequence of the significant mismatch between the thermal expansion coefficient (CTE) of the resin matrix and that of the reinforcing fibre. A typical cure profile involves an early heating ramp during which the uncured resin is in its liquid form and expands thermally without making any significant contribution to the curing process. The typical isothermal dwell stage that follows is accompanied by 
polymerisation shrinkage; finally thermal contraction occurs as the now solid composite is cooled down to room temperature. It is in this cooling stage that the most significant residual stresses are expected to be set up. Polymerisation shrinkage has been ignored to an extent, the argument being that it occurs at a relatively high temperature when the resin is in its rubbery $\operatorname{state}^{2}$. However, it has never been shown that polymerisation shrinkage in the resin, which can exceed $6 \%$ by volume ${ }^{3}$, is able to relax mechanically. Indeed there are numerous additives, such as montmorillorite clays ${ }^{4}$ and various thermoplastics ${ }^{5,6}$, which are routinely used in an attempt to counteract thermosetting resin shrinkage in a variety of fibre reinforced composites.

The level of modelling of composites manufacturing processes has improved significantly in recent years, but further progress is likely to be limited by the lack of verified data on the cure dependent properties of resins ${ }^{7-9}$. It is therefore timely to produce better quality raw data to feed into such models ${ }^{10}$. The present paper describes the development of a methodology for thermo-analytical characterisation of an unreinforced thermoset, with the emphasis on following the conversion dependent changes in the volume and the coefficient of thermal expansion of the resin as it is curing. The experimental methods used range from basic thermal analysis, to rheometry and liquid-solid dilatometry. A proprietary thermoplastic-modified epoxy resin, formulated for $160^{\circ} \mathrm{C}$ cure, was selected for practical measurement reasons, as it exhibits a relatively high chemical shrinkage. The chemical nature of the formulation is unimportant here and the detailed experimental and modelling methodology presented in this paper is seen as applicable to any epoxy based resin.

\section{METHODS}

The analytical tools that need to be built up in order to obtain a quantified description of the conversion dependent property profile of the resin are: (1) the kinetics of the curing reaction and the development of the glass-to-rubber transition temperature, $\mathrm{T}_{\mathrm{g}}$;

(2) identification of the gelation region; (3) dependence of the thermal expansion coefficient upon the state of the material, and (4) the dependence of the chemical shrinkage upon the degree of cure. The following subsections set out the experimental methods and associated theory that are necessary to the development of these analytical tools. 


\section{Cure kinetics and glass transition temperature}

Detailed knowledge of the chemical cure kinetics of the resin is an essential prerequisite of this study, in order that the measured changes in the resin can be associated with a known degree of cure at all stages of the cure. The raw data were obtained from a modulated differential scanning calorimeter (TA Instruments MDSC Model 2920). Measurements were made in dynamic mode between $-50^{\circ} \mathrm{C}$ and $320^{\circ} \mathrm{C}$ at a range of heating rates between 1 and $20 \mathrm{~K} \mathrm{~min}^{-1}$ /, and subsequently under isothermal conditions at a number of set temperatures $\left(120^{\circ} \mathrm{C}-200^{\circ} \mathrm{C}\right)$. About a hundred samples were used to obtain the data set and examples of raw data obtained are shown in Fig. 1. The equilibration to the required isothermal temperature occurred without any significant temperature overshoot (see Fig.1a). Details of standard data treatment, including the use of Bandara's baseline (see Fig.1b), can be found in reference 11.

The chemical cure kinetics were modelled using a modified expression of $\mathrm{n}^{\text {th }}$ order, combining autocatalytic and diffusion control models, as follows:

$\frac{d \alpha}{d t}=k_{1} \cdot(1-\alpha)^{n_{1}}+k_{2} \cdot(1-\alpha)^{n_{2}} \cdot \alpha^{m}$

where $\alpha$ is the degree of conversion, $\mathrm{k}_{\mathrm{i}}$ is a reaction rate coefficient and $\mathrm{n}_{1}, \mathrm{n}_{2}, \mathrm{~m}$ are adjustable parameters. The diffusion controlled aspects of the process can be expressed by adopting the following expression for the reaction rate:

$\frac{1}{k}=\frac{1}{k_{c h}}+\frac{1}{k_{\text {diff }}}$

in which

$$
k_{c h}=A_{c h} \cdot \exp \left(-\frac{E_{c h}}{R \cdot T}\right)
$$

where the subscripts $c h$ and diff refer respectively to chemical hardening and diffusion. Thus $\mathrm{A}_{c h}$ is the Arrhenius pre-exponential constant, and $\mathrm{E}_{c h}$ is the activation energy for the chemical hardening reaction and $\mathrm{R}$ is the universal gas constant. 
Then, $k_{\text {diff }}$ describes the diffusion mechanism, by:

$k_{\text {diff }}=A_{\text {diff }} \cdot \exp \left(-\frac{E_{\text {diff }}}{R \cdot T}\right) \cdot \exp \left(-\frac{b}{f}\right)$

where $\mathrm{b}$ is a fitting parameter, and the constants $\mathrm{A}_{\text {diff }}$ and $\mathrm{E}_{\text {diff }}$ are similar equivalent to those in Eq.3 but valid for those regions of the cure where diffusion limitations dominate.

Finally, $f$ represents the free volume fraction of the total volume of the material at temperature $\mathrm{T}$, which is a function of the glass transition temperature $\mathrm{T}_{\mathrm{g}}$ and the conversion $\alpha$ :

$$
f=0.00048 \cdot\left[T-T_{g}(\alpha)\right]
$$

The activation energy $\mathrm{E}_{\text {diff }}$ can vary over five orders of magnitude. This makes it difficult to select appropriate initial points for the fitting procedure. In a previous cure kinetics study in our group ${ }^{12}$, the starting points for the numerical fitting were selected from some knowledge, albeit limited, of the chemical composition of the resin. In the present study, the chemical composition of the resin was unknown. The problem was resolved by using a genetic algorithm to locate the region of the absolute minimum of the least squares function and then using non -linear least squares fitting tools to identify the optimum parameters ${ }^{13}$. A hybrid genetic algorithm was used to fit the model described by Eqs. 1-5 to the complete set of experimental DSC data. A single set of parameters, valid for both $\underline{\text { dynamic }}$ and isothermal measurement conditions, was obtained.

Equation 5 expresses the dependence of the factors governing diffusion rates in the curing resin upon its instantaneous glass transition temperature. The existence of a unique relationship between the degree of conversion, $\alpha$, of a thermosetting polymer and its glass transition temperature, $T_{g}$, has been demonstrated by previous workers ${ }^{14-16}$. In order to link the development of $T_{g}$ with the progress of the reaction, the glass transition temperatures of a number of partially cured resin samples were measured using DSC. The samples were prepared by curing the resin in the DSC apparatus, under 
either dynamic heating conditions $\left(1-20 \mathrm{~K} \mathrm{~min}^{-1}\right)$ or under isothermal conditions (120 $-180^{\circ} \mathrm{C}$ ) for different times and subsequently quenching them rapidly in liquid nitrogen. It was necessary to prepare and test fifty such specimens in order to cover the whole accessible range of conversions. The fast cooling of the samples was intended to limit any physical aging problems due to spontaneous densification of the resin; it was found that characteristic physical aging peaks were absent from the subsequent DSC thermograms. The $T_{g}$ values were determined as the inflection points of the heat flow step in the DSC signal in a thermal scan at $10 \mathrm{~K} \mathrm{~min}^{-1}$.

\section{Identifying the gelation time region}

The experimental identification of the cure time or conversion at which the thermoset may be assumed to have formed a three-dimensional (i.e. has gelled) remains a topic for discussion. It is common to use rheometric techniques to arrive at an operational definition of gelation, $t_{\text {gel }}$, by selecting either the time at which the resin reaches an arbitrary (high) viscosity value ${ }^{17}$ or the point at which at which curves for the storage and loss components of the complex shear modulus cross over ${ }^{18}$. In this work, measurements were carried out using a Bohlin CV 10 rheometer, oscillating at $0.5 \mathrm{~Hz}$, with a parallel plate configuration at gap setting of $0.5 \mathrm{~mm}$.

\section{Coefficient of thermal expansion (CTE)}

The thermal expansion coefficients of five different, partially cured, resin plate samples were measured using a thermal mechanical analyser (TMA - TA Instruments Model 2940) fitted with a standard expansion probe. Specimens with dimensions $3 \times 3 \times 15 \mathrm{~mm}$ were cut and shaped from the plates. After placing the specimen in the cell and equilibrating the temperature at $30^{\circ} \mathrm{C}$, the linear dimension of the sample was monitored up to $310^{\circ} \mathrm{C}$, at a heating rate of $2 \mathrm{~K} \mathrm{~min}^{-1}$. The minimum attainable force of $2 \mathrm{mN}$ was applied to maintain contact between the probe and the sample. The coefficient of thermal expansion of the material in its glassy state is the slope of the displacementtemperature curve at temperatures below the appropriate glass transition temperature. As this part of the curve was reasonably linear, the CTE values were determined from a simple linear fit, starting from $30^{\circ} \mathrm{C}$. At temperatures above the $\mathrm{T}_{\mathrm{g}}$ of of the partially cured samples, this means of determination of the CTE becomes inappropriate, partly because of possible probe penetration, but also because the sample will undergo post- 
cure. The coefficient of thermal expansion above the $T_{g}$ was therefore determined only in the case of fully cured sample, by linear fitting of the displacement versus temperature curve.

\section{Chemical shrinkage}

Measurements of specific volume during isothermal cure of the resin were performed using an improved version of the Pressure-Volume-Temperature (PVT) GNOMIX equipment, at the National Physical Laboratory ${ }^{19}$. The equipment uses an LVDT to measure changes in the linear dimensions of a cylindrical specimen, heated by a surrounding electrical coil. A liquid resin sample weighing about $1 \mathrm{~g}$, previously degassed for $45 \mathrm{~min}$ at $100^{\circ} \mathrm{C}$, was poured into the cell, heated up and held at the test temperature.

\section{RESULTS}

\section{Data from DSC}

The glass transition temperatures, the residual heats of reaction and the degrees of cure of the individual resin plate samples A to E are summarised in Table 1, together with the corresponding measured values of the coefficient of thermal expansion (CTE). The scatter in $T_{g}$ values specified in the table was determined by separate DSC measurements on two samples from each corner and from the centre of each resin plate, at two different depths within a plate. The spatial variation in crosslink density calculated from these measurements is less than $1 \%$ within any one resin plate. The CTE values quoted represent an average of three measurements.

The agreement between the predictions of the cure kinetics model and the experimental data from DSC tests was very satisfactory, as shown in Fig.2a for isothermal cures at $120,140,160$ and $180^{\circ} \mathrm{C}$ and in Figure $2 \mathrm{~b}$ for dynamic cures carried out at heating rates between 1 and $20 \mathrm{~K} \mathrm{~min}^{-1}$. In selecting parameters fort the model, the target across this wide range of processing conditions was an optimum fit for the gelation and postgelation stages of cure.

Figure 3 illustrates the dependence of the experimentally measured $\mathrm{T}_{\mathrm{g}}$ on the fractional conversion $\alpha$. The model relating these two material quantities was taken from previous 
work ${ }^{17,18}$ and is based on the application of DiBenedetto's equation (Eq.6). A satisfactory fit of the model to experimental data is obtained.

$$
\operatorname{Tg}(\alpha)=T_{g 0}+\left(T_{g 0}-T_{g \infty}\right) \frac{(1-\alpha) \cdot \lambda}{1-(1-\lambda) \cdot \alpha}
$$

where $T_{g 0}=-10^{\circ} \mathrm{C}$ and $T_{g \infty}=185^{\circ} \mathrm{C}$ are the glass transition temperatures of the uncured and of the 'fully' cured resin respectively. In the present study, this particular resin can be assumed to be 'fully' cured at a conversion level of $96 \%$. The adjustable parameter $\lambda$ is characteristic for the system, and in this case takes the value of 0.656 .

\section{Rheology and thermal expansion data}

The rheometric experiments were carried out under isothermal conditions, at temperatures between $110^{\circ} \mathrm{C}$ and $170^{\circ} \mathrm{C}$. Figure 4 shows the determination of time to gelation $\left(\mathrm{t}_{\mathrm{gel}}\right)$ at $140^{\circ} \mathrm{C}$ from the point of the crossover between $\mathrm{G}^{\prime}$ and $\mathrm{G}^{\prime \prime}$, the storage and loss components of the complex shear modulus when plotted against conversion $\alpha$. The resin is expected to gel after about 91 minutes of cure at $140^{\circ} \mathrm{C}$. The corresponding fractional conversion, as calculated using the cure kinetics model, is $\alpha=0.64$. The equivalent values for cure at $120^{\circ} \mathrm{C}$ are 205 minutes and $\alpha=0.653$. Gelation times for isothermal cures decrease with increasing cure temperature. There is a linear relationship between the logarithm of time to gelation and the inverse of (absolute) temperature, as shown in Fig. 5. The degree of conversion corresponding to the formation of the 3D network is fairly constant, in the range of 0.64-0.66.

Figure 6 shows the linear displacement, from TMA measurements, as a function of temperature for the different resin plate samples. The shape of the curve obtained from the fully cured sample is as expected, with a classical indication of the glass transition temperature at around $190^{\circ} \mathrm{C}$ from these measurements (c.f. $T_{g_{\infty}}=185^{\circ} \mathrm{C}$ from DSC). The shapes of the curves for the partially cured resin samples indicate the onset of residual reaction; there is a shoulder immediately after the $T_{g}$, followed by the combined effects of reaction shrinkage and thermal expansion.

The heating period in the liquid dilatometry experiments was used to determine the coefficient of thermal expansion of the liquid unreacted resin, which was found to be $248 \times 10^{-6} \mathrm{~K}^{-1}$. The coefficient of thermal expansion above the $\mathrm{T}_{\mathrm{g}}$, for fully cured material, was determined from the final slope of the appropriate displacement versus 
temperature curve in Fig. 6, and found to be $136 \times 10^{-6} \mathrm{~K}^{-1}$. The CTE values for the material in the glassy state, as reported in Table 1, exhibit a linear dependence on the conversion (Fig.7).

\section{Chemical shrinkage}

Figure 8 illustrates the changes in specific volume occurring during cure at two isothermal temperatures, namely $140^{\circ} \mathrm{C}$ and $160^{\circ} \mathrm{C}$. The initial rapid expansion in volume is dominated by the thermal expansion of the sample from $80^{\circ} \mathrm{C}$ to the cure temperature. The volume data are presented alongside the corresponding degree of conversion, and the gelation region is indicated. The difference between the final specific volumes of vitrified samples cured at the two different temperatures indicates that the overall volume reduction in a sample depends strongly on the exact thermal history of that sample. Figure 9 shows that the chemical shrinkage is a linear function of the degree of conversion, in this particular resin, implying that the resin shrinkage coefficient is constant throughout the cure.

\section{SIMULATIONS FOR NON-ISOTHERMAL CURES}

The results of the experimental part of this study establish that both the chemical shrinkage of the resin and its coefficient of thermal expansion in the glassy state above conversion levels of 0.68 depend linearly on the degree of cure. The assumption that the CTE is linearly dependent on the degree of cure in the liquid and rubbery states enables the experimental data reported previously to be translated to a model for volume changes, based on the following relationship:

$$
\frac{d \hat{V}}{d t}=\hat{V} \cdot\left(\alpha_{v} \cdot \frac{d T}{d t}-\gamma \cdot \frac{d \alpha}{d t}\right)
$$

Where $\hat{V}$ is the specific volume, $\alpha_{v}$ is the volumetric coefficient of thermal expansion (VCTE) and $\gamma$ is the (constant) resin shrinkage coefficient with respect to the degree of cure.

Use of the discrete form of Eq. 7 yields 
$V_{i}=\frac{V_{i-1}}{1+\alpha_{v} \cdot \Delta T-\gamma \cdot \Delta \alpha}$

where $V_{i}$ and $V_{i-1}$ denote the specific volume at times $t_{i}$ and $t_{i-1}$ respectively; $\Delta T$ and $\Delta \alpha$ denote the change in temperature and conversion respectively, from $t_{i-1}$ to $t_{i}$. The simulation used to model volumetric changes operates incrementally as suggested by Eq. 8 . In each time step the change in conversion is calculated using the kinetic model described by Eqs. 1-5. Then a comparison is made between the actual temperature of the material and the instantaneous glass transition temperature in order to determine whether the resin is in the rubbery or glassy state, and the appropriate coefficient of thermal expansion is input in Eq. 8. A schematic diagram of the algorithm used is given in Fig. 10.

The model was used to simulate the volumetric changes expected during two typical non-isothermal cure cycles; in the first cure the resin is expected to vitrify during the isothermal dwell, while in the second the resin is expected not to reach vitrification before being cooled down. The results are illustrated in Fig 11.

During the heating ramp stage, resin expansion occurs as the result of two opposing effects: thermal expansion and the early stages of chemical shrinkage. In the isothermal stage chemical shrinkage is the only active phenomenon. In this stage the rate of change of specific volume reflects the rate of the reaction, and therefore becomes low towards the end. Under the conditions represented in Fig.11a, the resin vitrified prior to cooling and thus the specific volume against cure time plot in that stage is a straight line corresponding to simple contraction of the glassy thermoset. In Fig.11b, the passage of the non-vitrified resin through its $T_{g}$, as it cooled down is indicated by the intersection of the dotted lines.

\section{CONCLUSIONS}

The modelling methodology outlined here appears to be an appropriate way to account for the volumetric changes occurring during the cure of a thermosetting resin. As a next step, such methodology can be integrated within more complex simulation tools relating to the manufacture of thermosetting composites, such as heat transfer models or residual 
stress development simulations ${ }^{20}$. Our future publications will provide the necessary complementary data on the development of the viscoelastic modulus in the curing resin, to make the connection between the state of the material and existing models for warpage in composite parts.

\section{ACKNOWLEDGEMENTS}

This work was funded by the EPSRC (GR/M 89454). Access to the TMA equipment in the laboratories of the CIRA (Italy) and the practical assistance with PVT measurements by Dr C Hobbs at the National Physical Laboratory (UK) are gratefully acknowledged.

\section{REFERENCES}

1 S L Simon, G B McKenna and O Sindt: J Appl Polym Sci, 2000, 76, 495-508

2 H T Hahn and N J Pagano: J Compos Mater , 1975, 9, 91- 104

3 B Yates, B A McCalla, L N Phillips, D M Kingston-Lee and K F Rogers : $J$ Mater Sci, 1979, 14, 1207-1217

4 E Haque and C D Armeniades: Polym Eng Sci, 1986, 26, 1524-1530

5 M Kinkelaar and L J Lee: J Appl Polym Sci, 1992, 45, 37 - 42

6 C B Bucknall, I K Partridge and M J Phillips, Polymer, 1991, 32, pp. 636- 640

7 Y K Kim and S R White: Mechanics of Composite Materials and Structures, 1998, 5, 2-16.

8 T A Bogetti and J W Gillespie Jr. : J Compos Mater, 1992, 26/5, 626-660.

$9 \quad$ S R White and H T Hahn : J Compos Mater, 1993, 27/14, 698-711.

10 D J O`Brien, P T Mather and S R White : J Compos Mater, 2001, 35/16, 883902

11 U Bandara: J Thermal Anal, 1986, 31, 1063 -1071

12 P I Karkanas and I K Partridge: J Appl Polym Sci, 2000, 77, 1419-1431

13 M Mitchell: 'An introduction to genetic algorithms', 1998, MIT Press, US

14 L E Nielsen: J Macromol Sci, Revs Macromol Chem, 1969, 3, 69

15 J B Enns and J K Gillham: Adv Chem Ser, 1983, 203, 27 - 38

16 P Pang and J K Gillham: J Appl Polym Sci, 1990, 39, 909 - 915

17 P I Karkanas and I K Partridge : J Appl Polym Sci, 2000, 77, 2178-2188

18 H H Winter : Polym Eng Sci, 1987, 27, 1698-1702. 
Plastics, Rubber and Composites Processing and Applications 31(2002). 377-384

19 C B Hobbs and C S Brown : NPL report CMMT(A) 163, February 1999

20 P Prasatya, G B McKenna and S L Simon : J Compos Mater, 2001, 35, 826-847. 


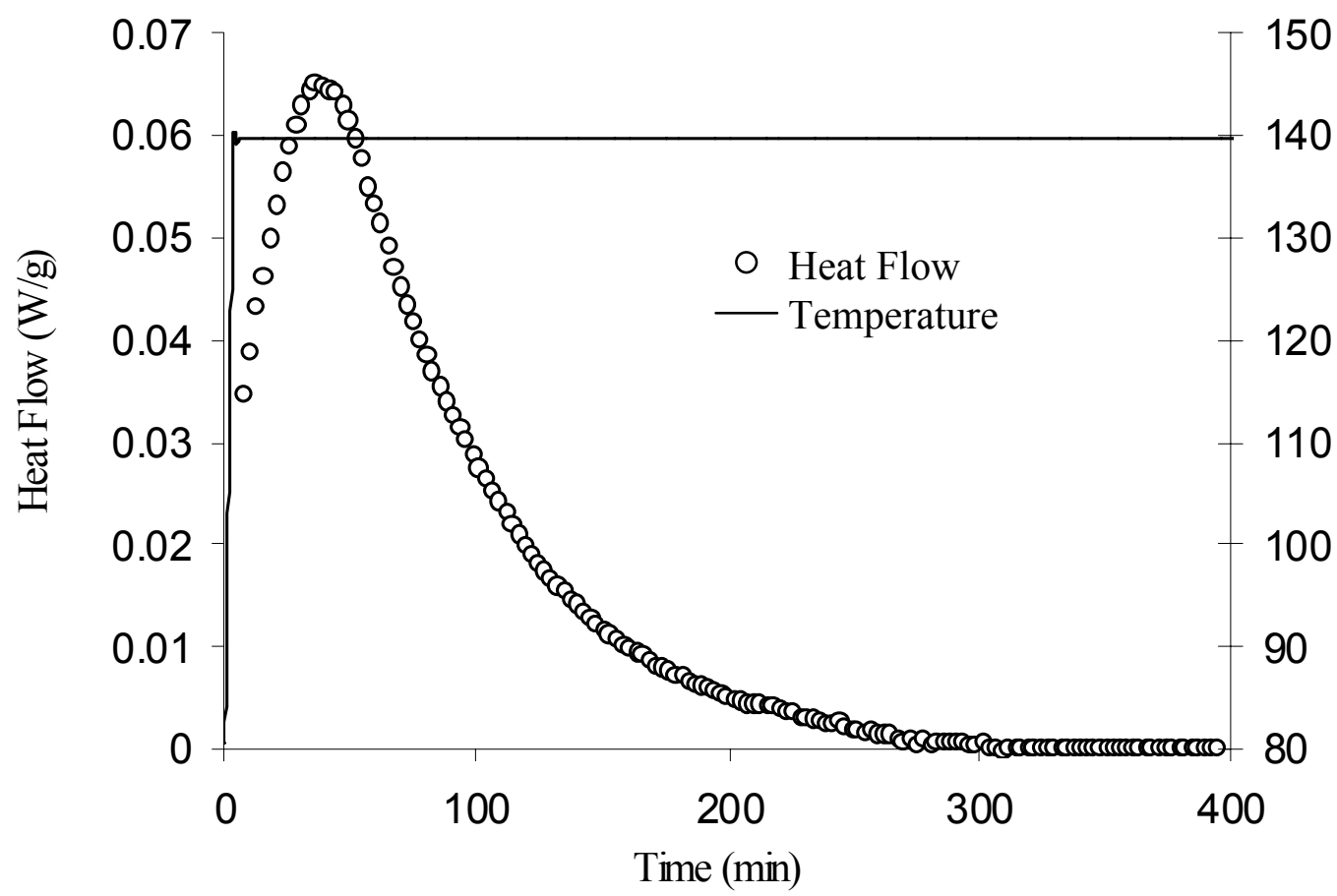

(a)

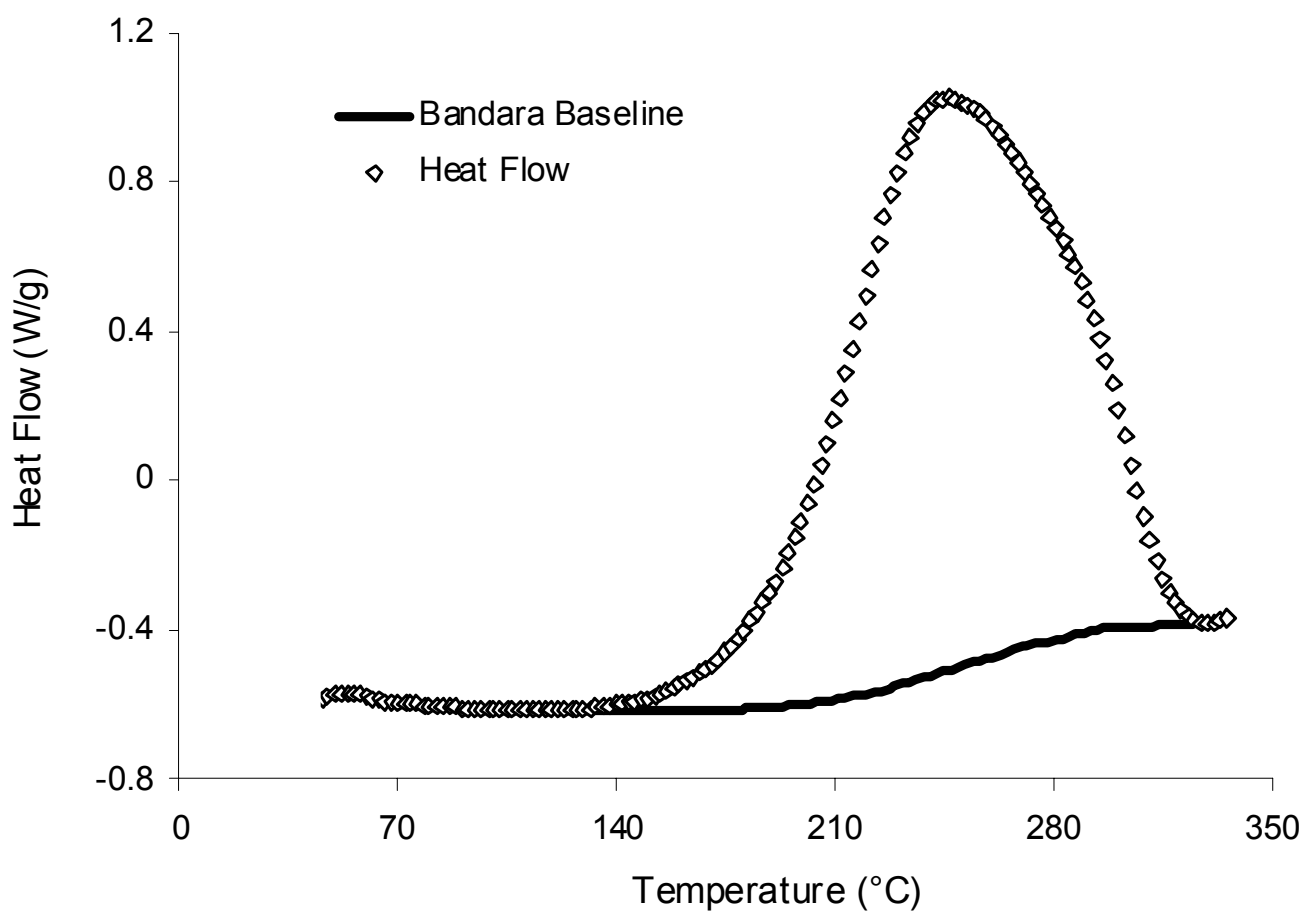

(b)

Figure 1 Raw data from DSC measurements carried out under (a) isothermal $\left(140^{\circ} \mathrm{C}\right.$ and (b) dynamic heating conditions $\left(20 \mathrm{~K} \mathrm{~min}^{-1}\right)$. Bandara baseline (lower curve) applied ${ }^{11}$ 
Table 1. Thermal analysis data for partially cured resin plates

\begin{tabular}{|c|c|c|c|c|}
\hline Plate & \multicolumn{1}{|l|}{$\left.\mathbf{T}_{\mathbf{g}} \mathbf{}^{\circ} \mathbf{C}\right)$} & $\begin{array}{l}\text { Residual heat of } \\
\text { reaction }(\mathbf{k J} / \mathbf{m o l})\end{array}$ & Degree of cure & Glass CTE $\left.\left(\mathbf{1 0}^{-\mathbf{6}} \mathbf{K}^{\mathbf{- 1}}\right)\right)$ \\
\hline A & $104 \pm 5$ & $132 \pm 3$ & 0.68 & 105 \\
\hline B & $133 \pm 3$ & $83 \pm 3$ & 0.80 & 79 \\
\hline C & $151 \pm 3$ & $54 \pm 3$ & 0.87 & 68 \\
\hline D & $165 \pm 3$ & $43 \pm 2$ & 0.90 & 49 \\
\hline E & $182 \pm 2$ & $18 \pm 1$ & 0.96 & 68 \\
\hline
\end{tabular}

Table 2. Parameters for the cure kinetics model

\begin{tabular}{|c|c|c|c|c|c|c|c|c|c|}
\hline $\begin{array}{c}\mathbf{A}_{\mathbf{1}} \\
\left(\mathrm{s}^{-1}\right)\end{array}$ & $\begin{array}{c}\mathbf{A}_{\mathbf{2}} \\
\left(\mathrm{s}^{-1}\right)\end{array}$ & $\begin{array}{c}\mathbf{A}_{\mathbf{d}} \\
\left(\mathrm{s}^{-1}\right)\end{array}$ & $\begin{array}{c}\mathbf{E}_{\mathbf{1}} \\
(\mathrm{kJ} / \mathrm{mol})\end{array}$ & $\begin{array}{c}\mathbf{E}_{\mathbf{2}} \\
(\mathrm{kJ} / \mathrm{mol})\end{array}$ & $\begin{array}{c}\mathbf{E}_{\mathbf{d}} \\
(\mathrm{kJ} / \mathrm{mol})\end{array}$ & $\mathbf{n}_{\mathbf{1}}$ & $\mathbf{n}_{\mathbf{2}}$ & $\mathbf{m}$ & $\mathbf{b}$ \\
\hline $2.51 \mathrm{E}+5$ & $1.72 \mathrm{E} 3$ & $2.6 \mathrm{E} 23$ & 78.99 & 50.25 & 126.0 & 0.813 & 2.361 & 0.581 & 0.302 \\
\hline
\end{tabular}

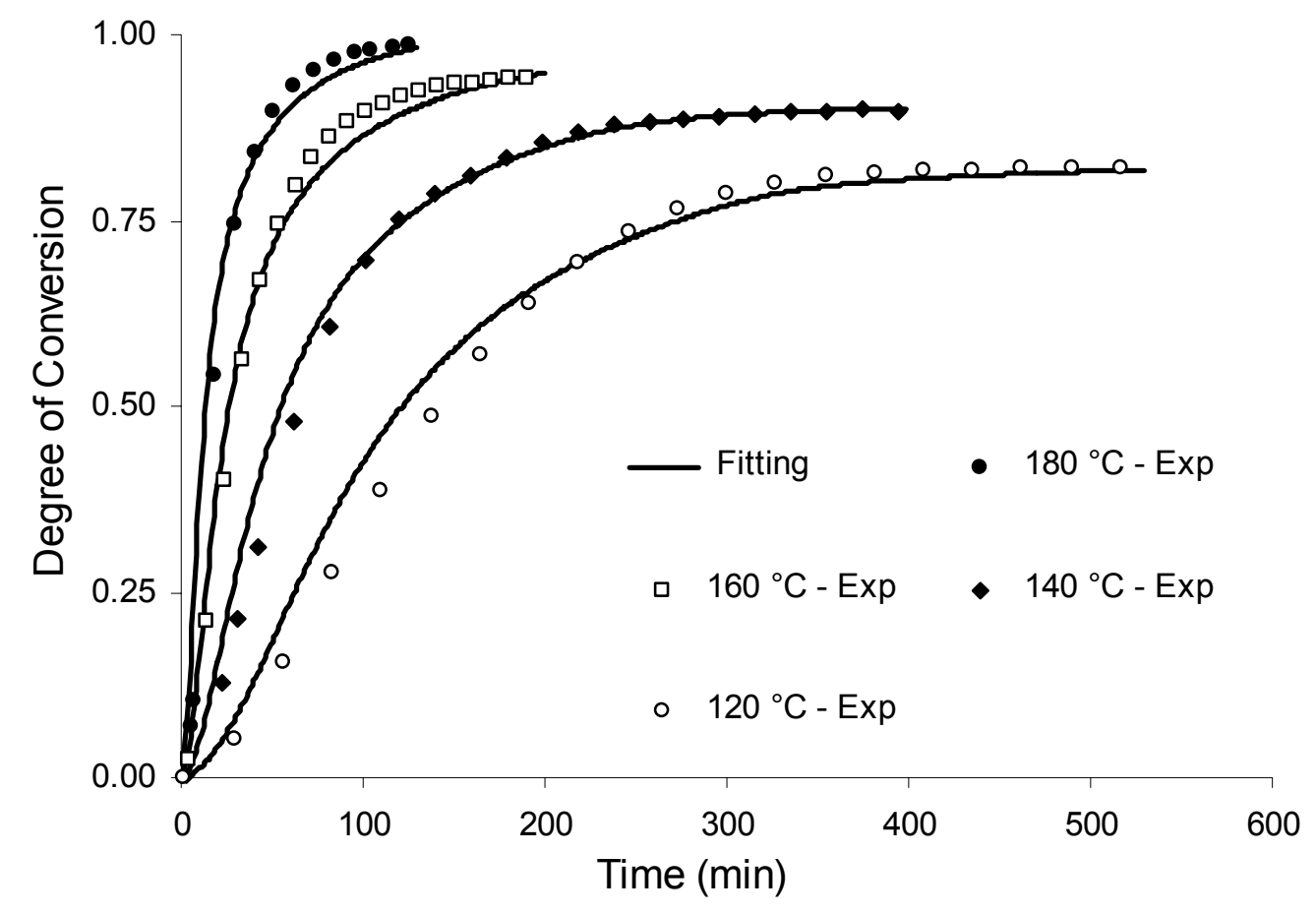

Fig. 2a. Comparison between experimental data from DSC and predictions of the cure kinetics model (solid lines) for isothermal cure conditions. 


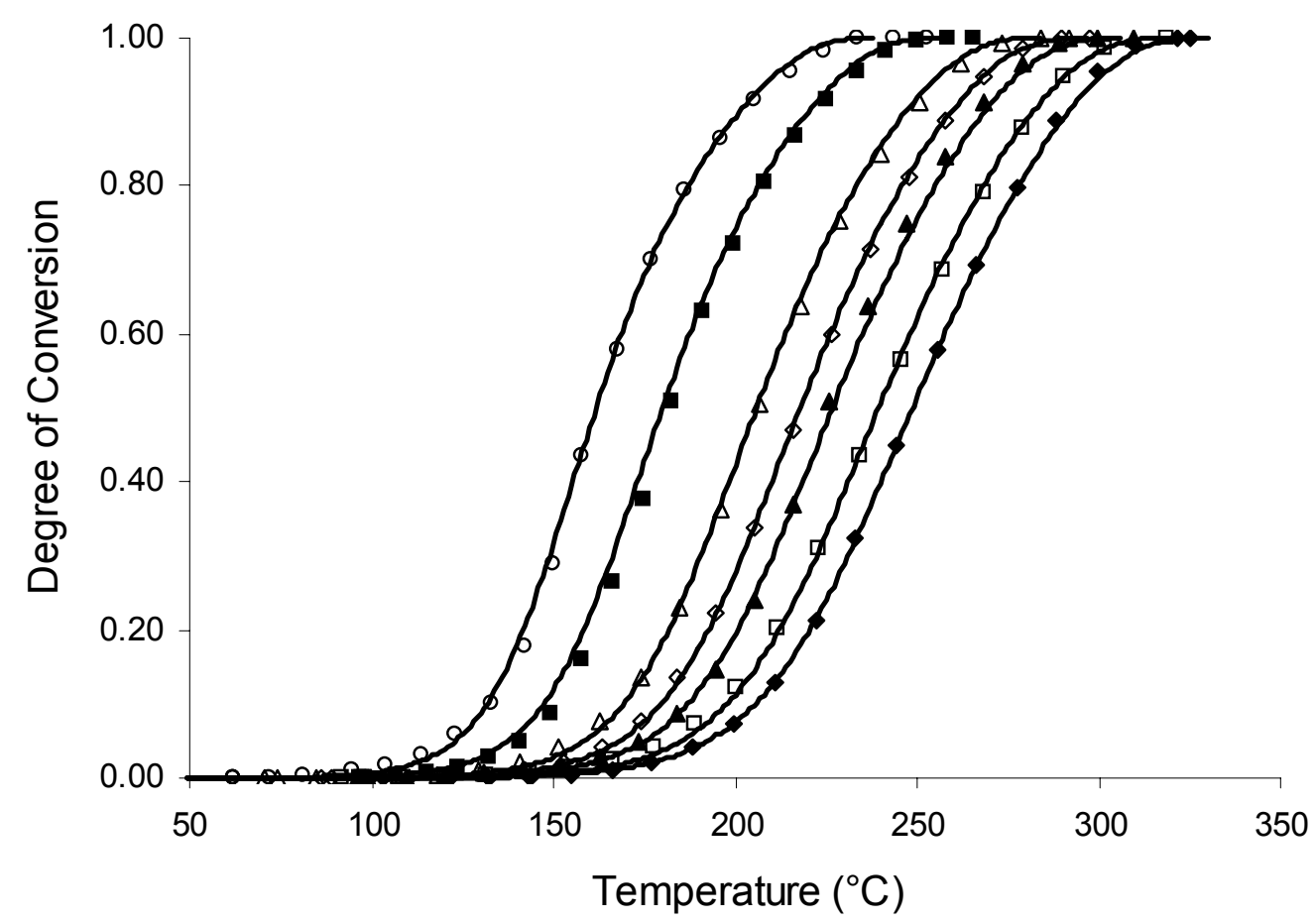

Fig. 2b. Comparison between experimental data from DSC and predictions of the cure kinetics model (solid lines) for dynamic cure conditions. (०)-1 ${ }^{\circ} \mathrm{C} / \mathrm{min},(-)-2{ }^{\circ} \mathrm{C} / \mathrm{min},(\triangle)-5{ }^{\circ} \mathrm{C} / \mathrm{min},(\diamond)-$ $7.5{ }^{\circ} \mathrm{C} / \mathrm{min},(\Delta)-10{ }^{\circ} \mathrm{C} / \mathrm{min},(\square)-15{ }^{\circ} \mathrm{C} / \mathrm{min}$, (•)-20 ${ }^{\circ} \mathrm{C} / \mathrm{min}$, (一)-Fitting

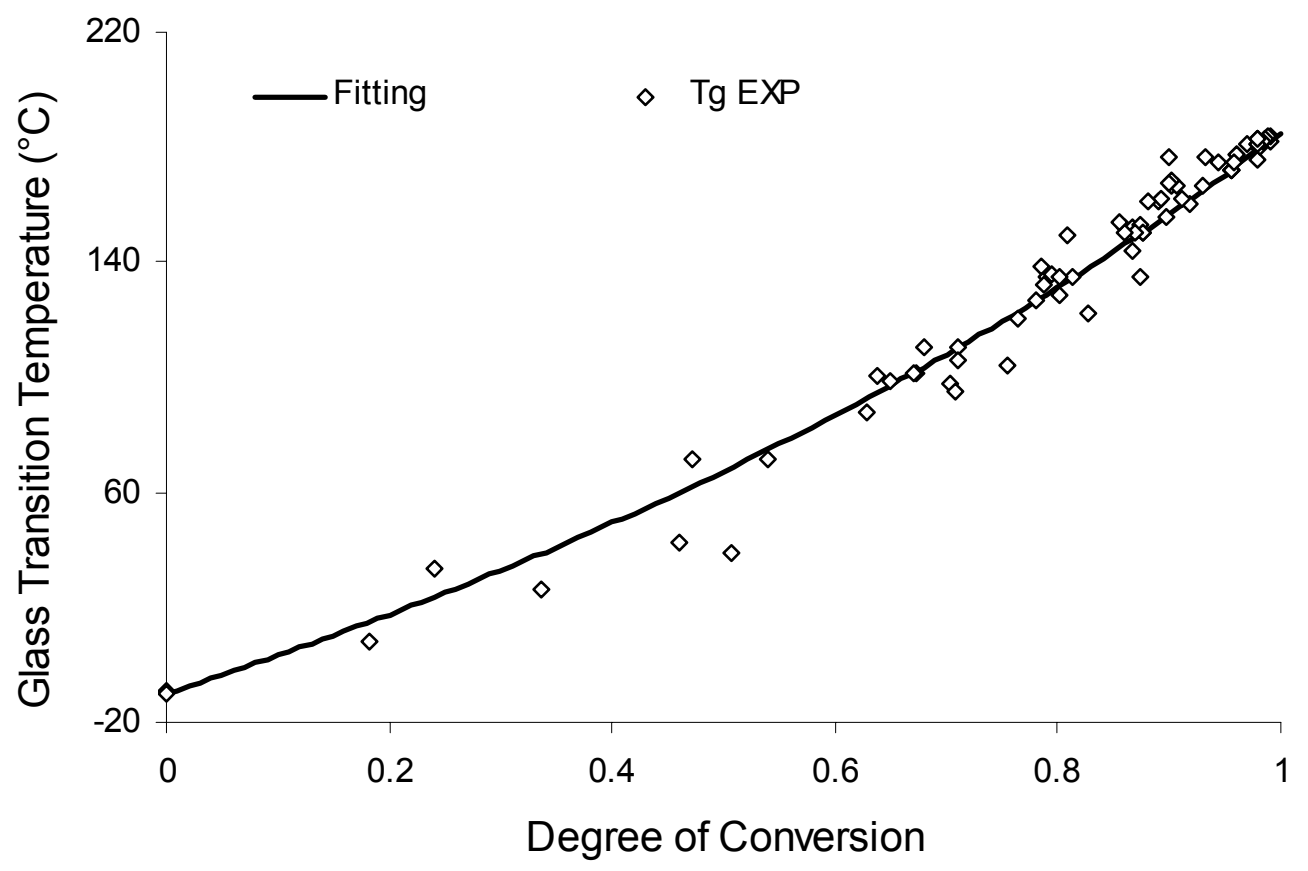

Fig. 3. Glass transition temperature versus conversion. Experimental data (EXP) and model fit. 


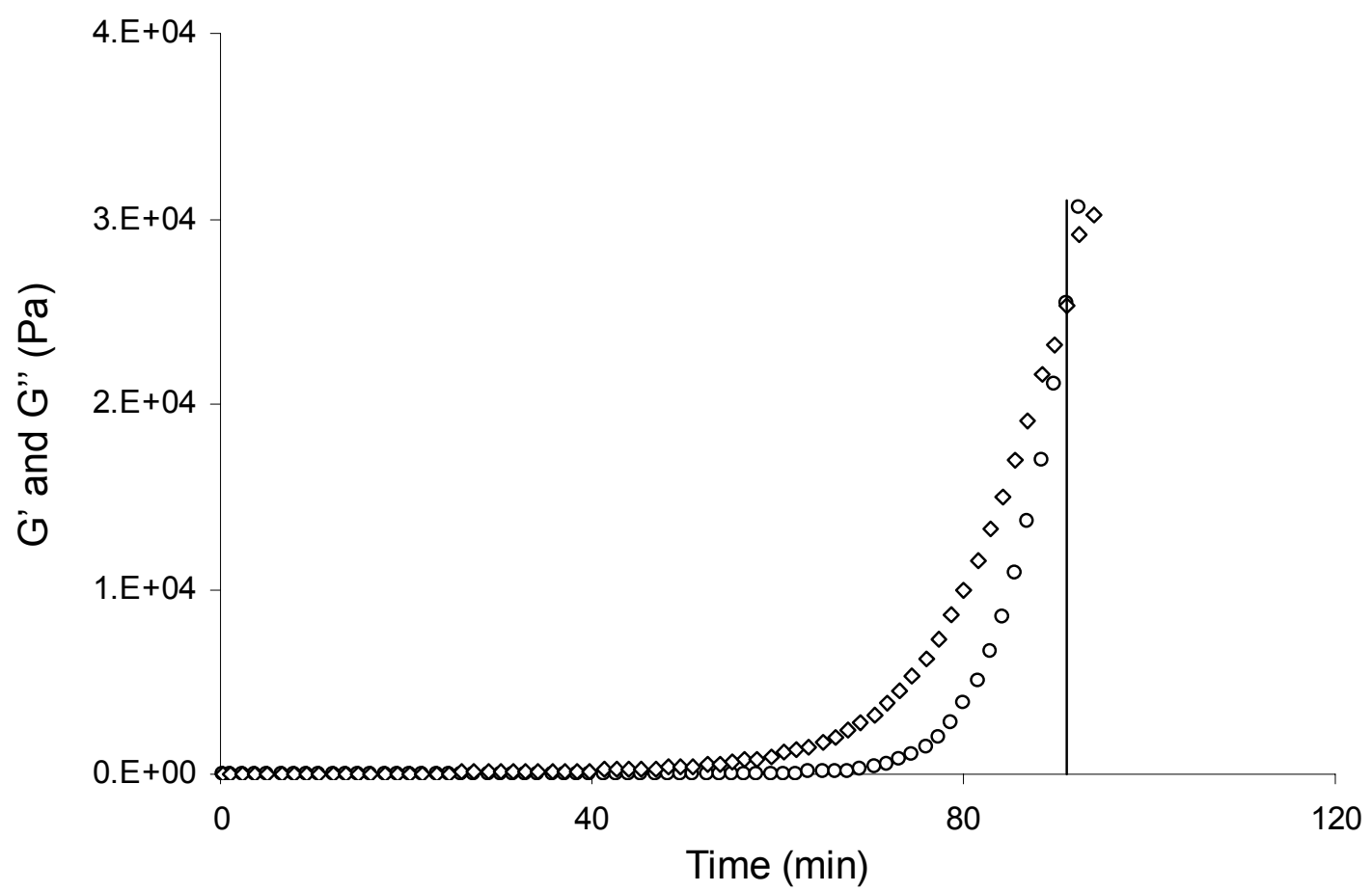

Fig. 4 Determination of time to gelation during $140^{\circ} \mathrm{C}$ isothermal cure. (०)-Storage modulus, $(\diamond)$-Loss modulus

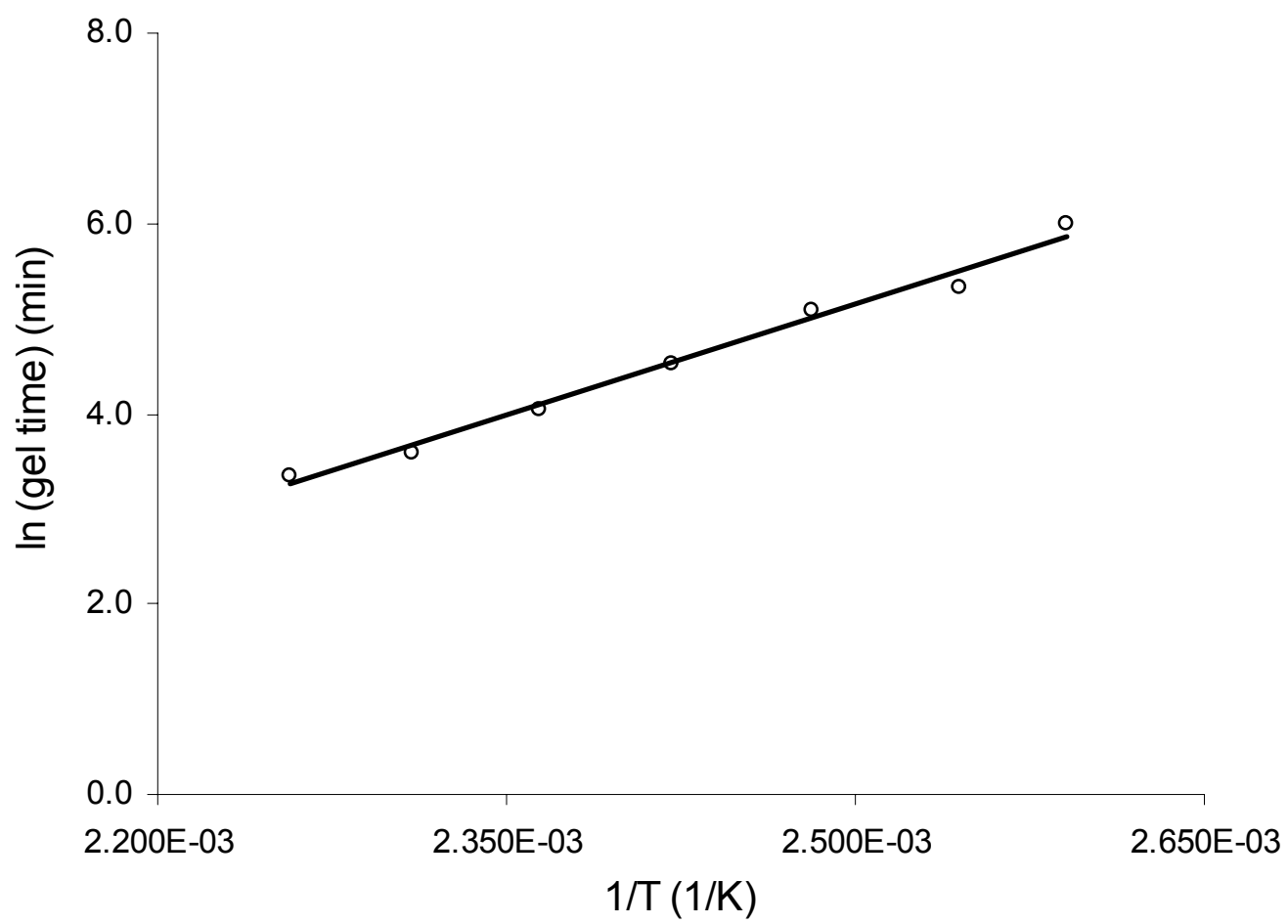

Fig. 5. Plot of the natural logarithm of the gelation time vs. inverse of absolute temperature. 


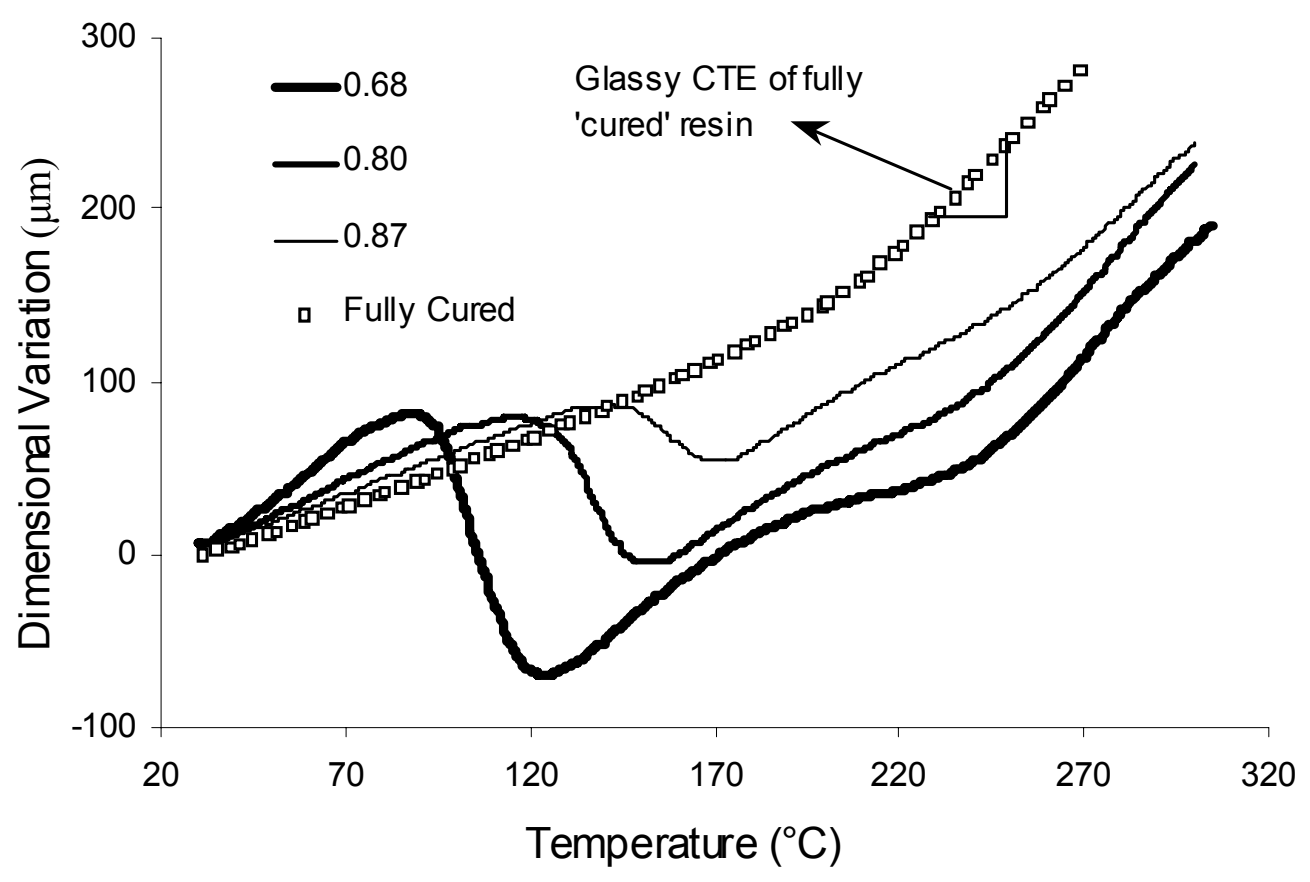

Fig. 6 Linear displacement versus temperature at various degrees of cure, determined by TMA.

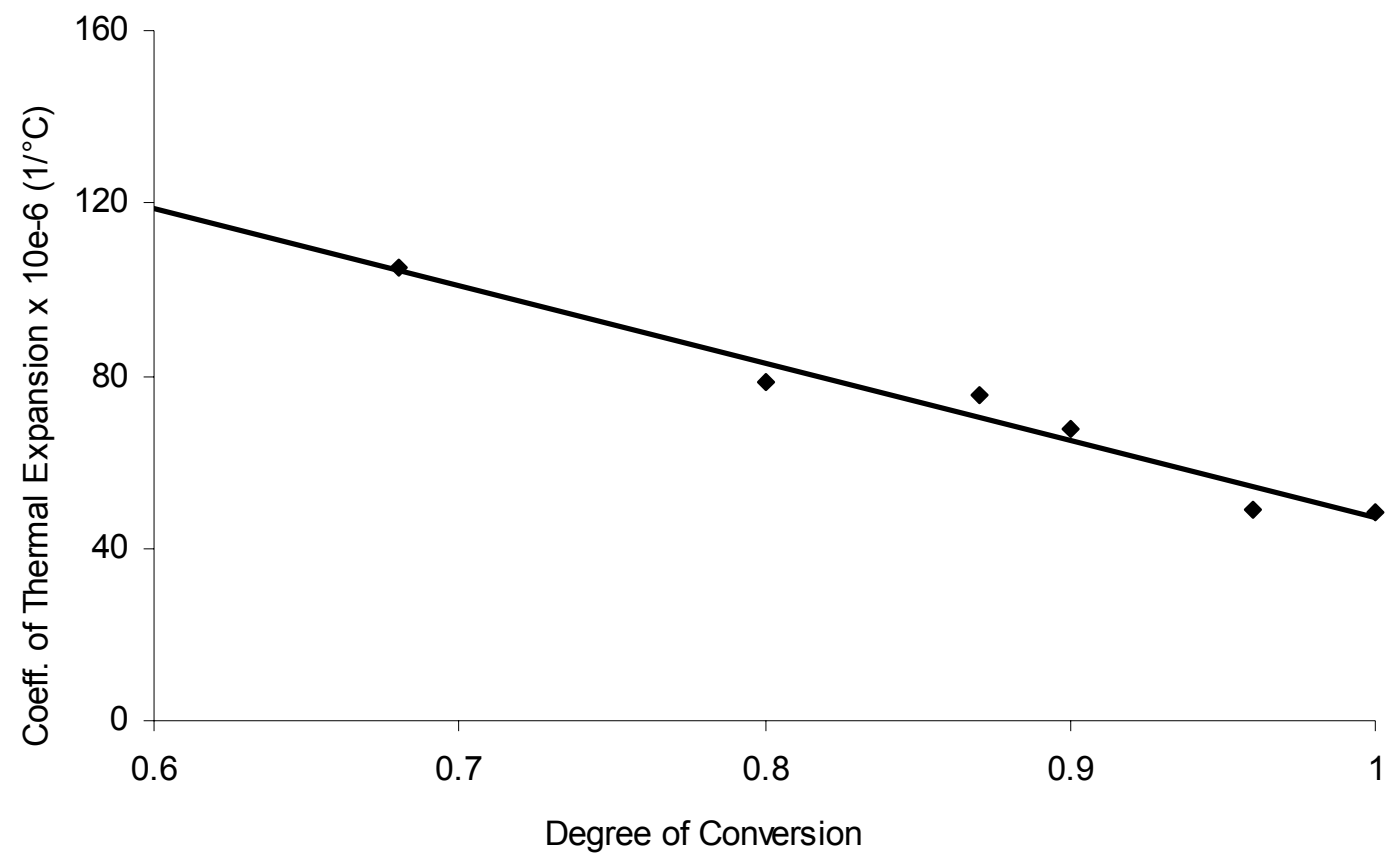

Fig. 7 Coefficient of thermal expansion versus conversion in the glassy state 


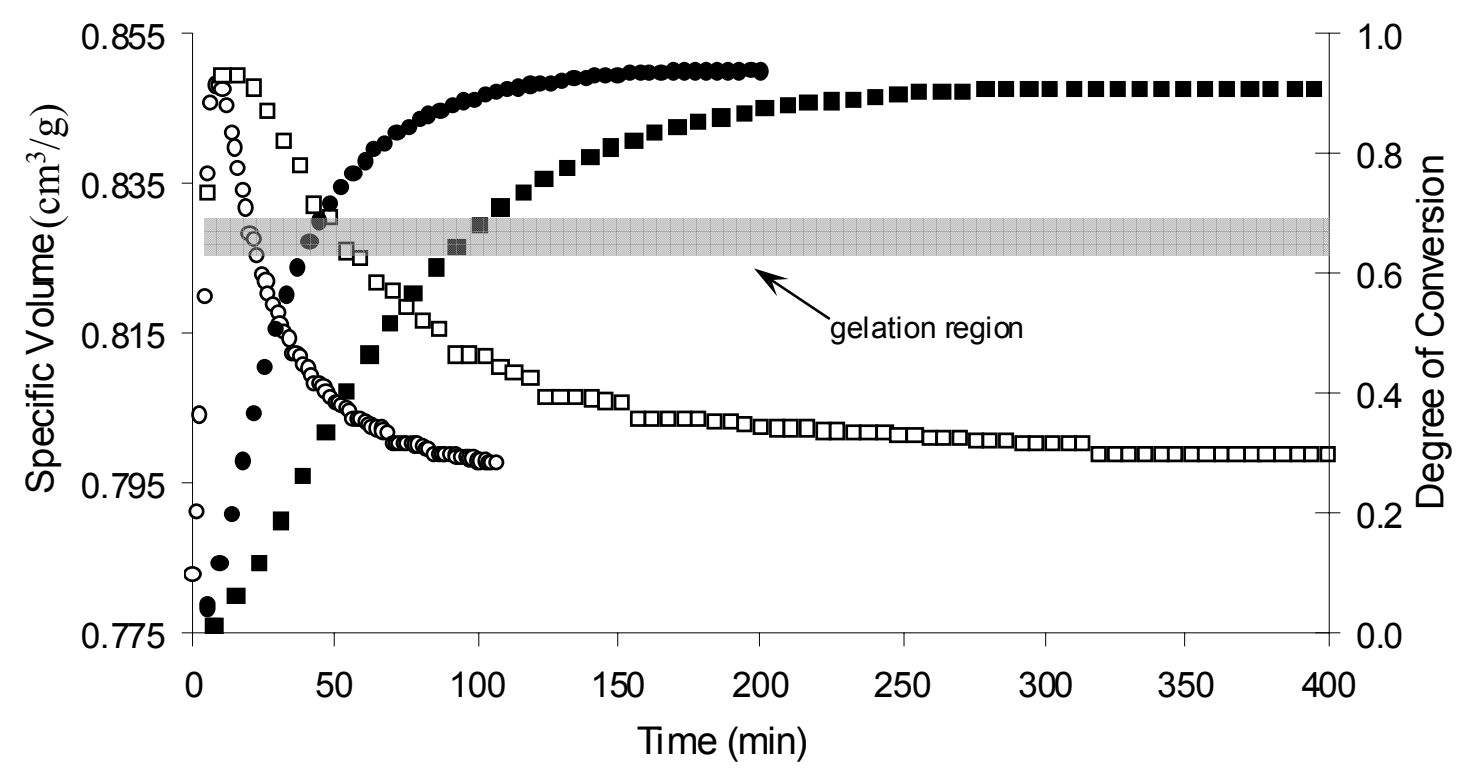

Fig. 8 Specific volume and fractional conversion versus cure time, for $140^{\circ} \mathrm{C}$ and $160^{\circ} \mathrm{C}$ isothermal cures. (०) - Specific Volume at $160^{\circ} \mathrm{C}$, (口) - Specific Volume at $140^{\circ} \mathrm{C}(\bullet)$ - Degree of Conversion at $160^{\circ} \mathrm{C},(\mathbf{-})-$ Degree of Conversion at $140^{\circ} \mathrm{C}$

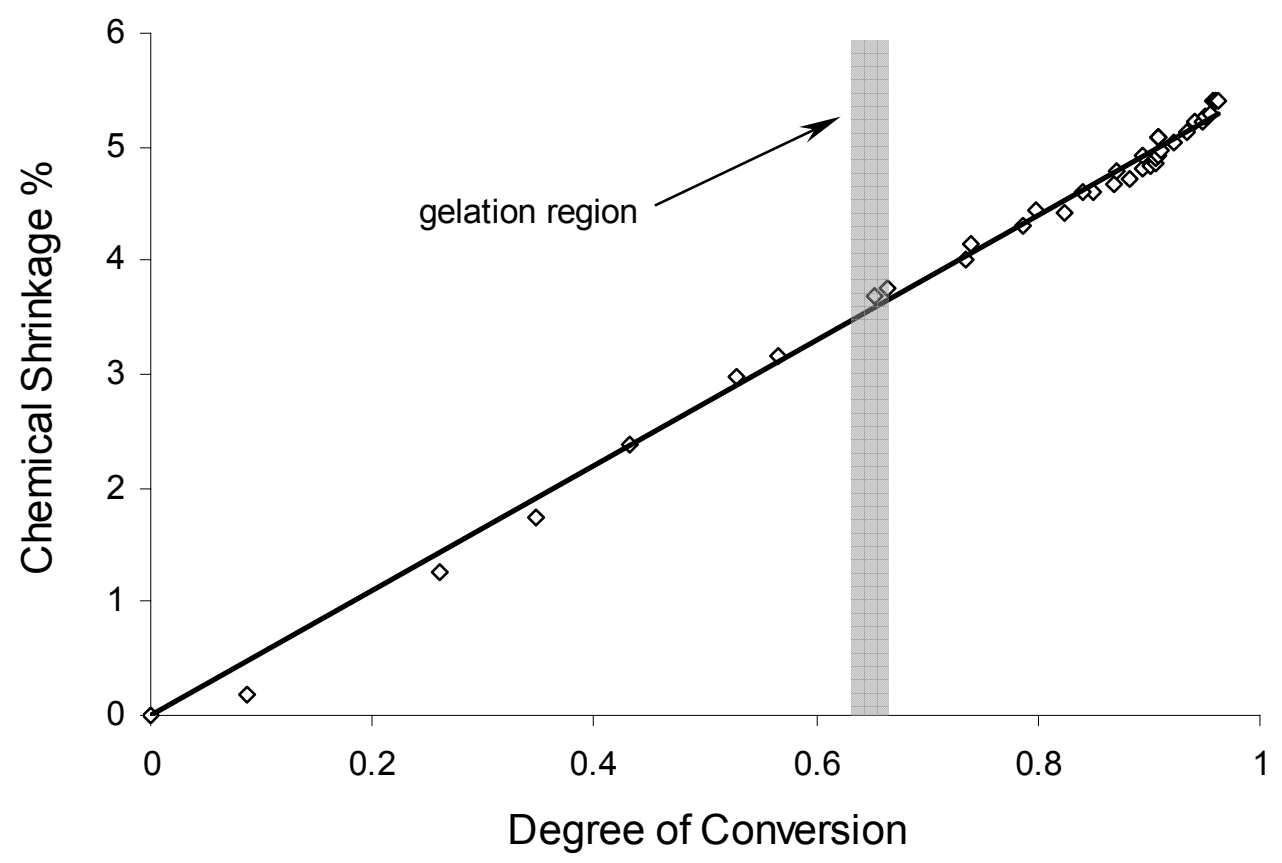

Fig. 9 Chemical shrinkage vs. degree of conversion for PVT test at $140^{\circ} \mathrm{C}$ and $160^{\circ} \mathrm{C}$ 


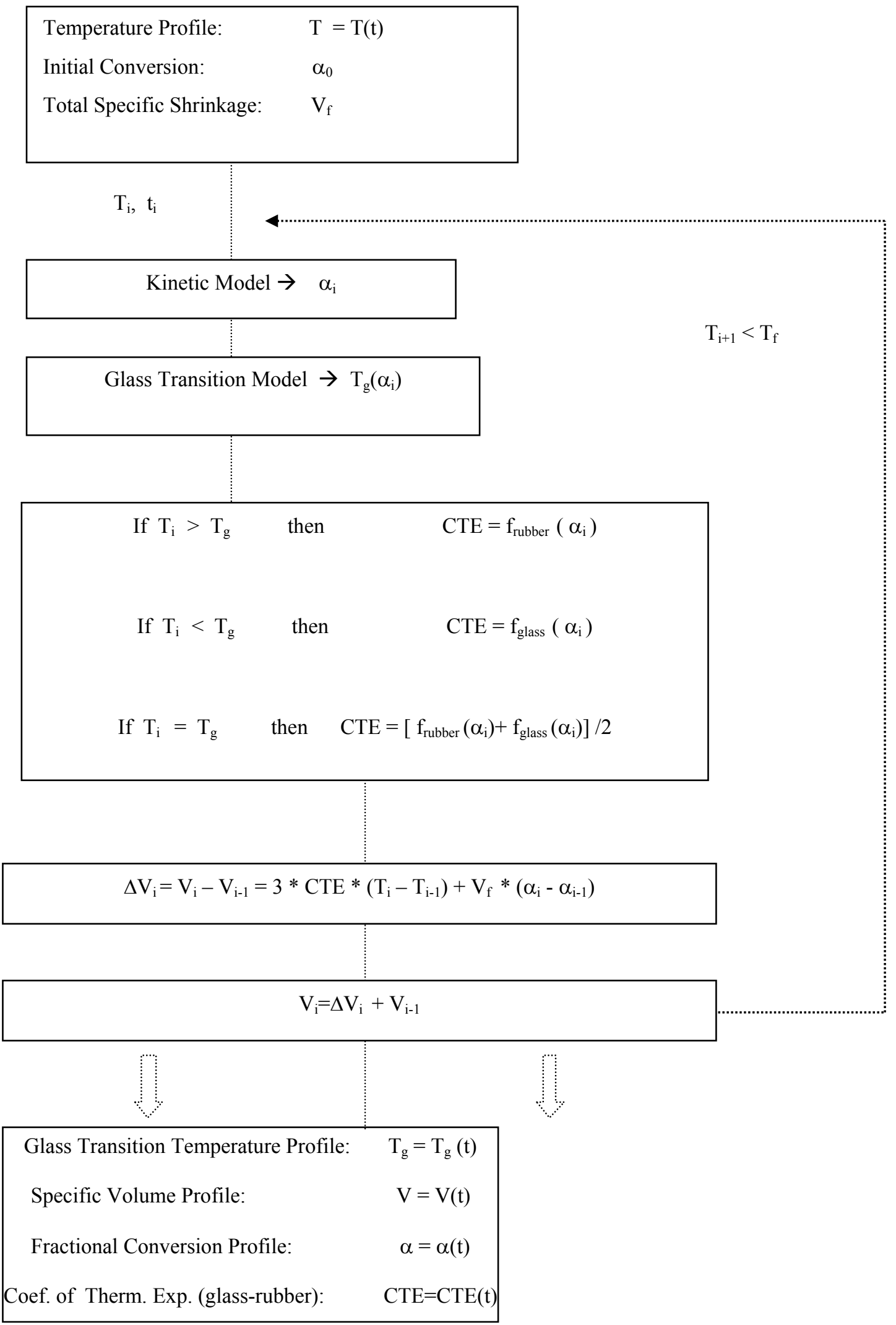

Fig. 10 Schematic representation of the algorithm. 


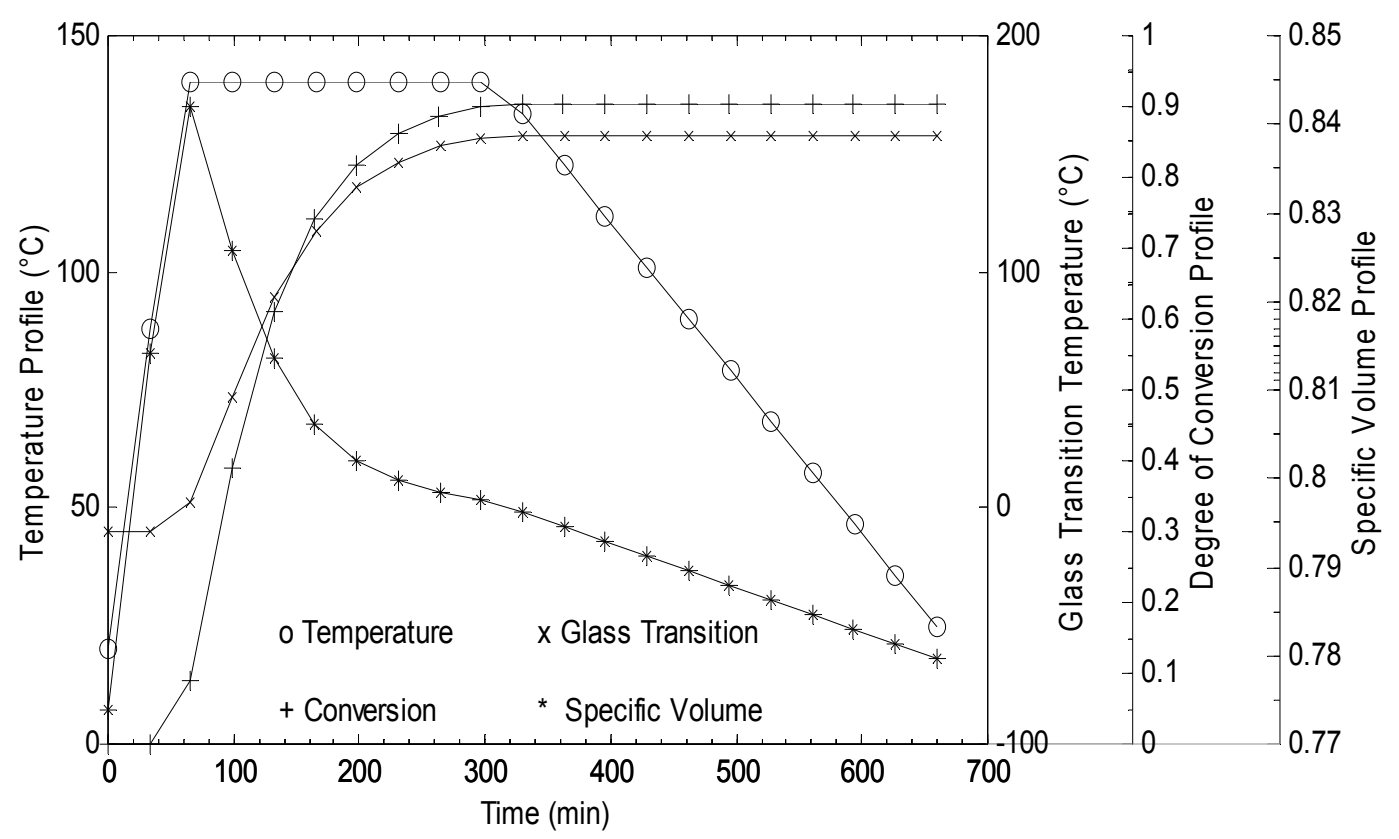

(a)

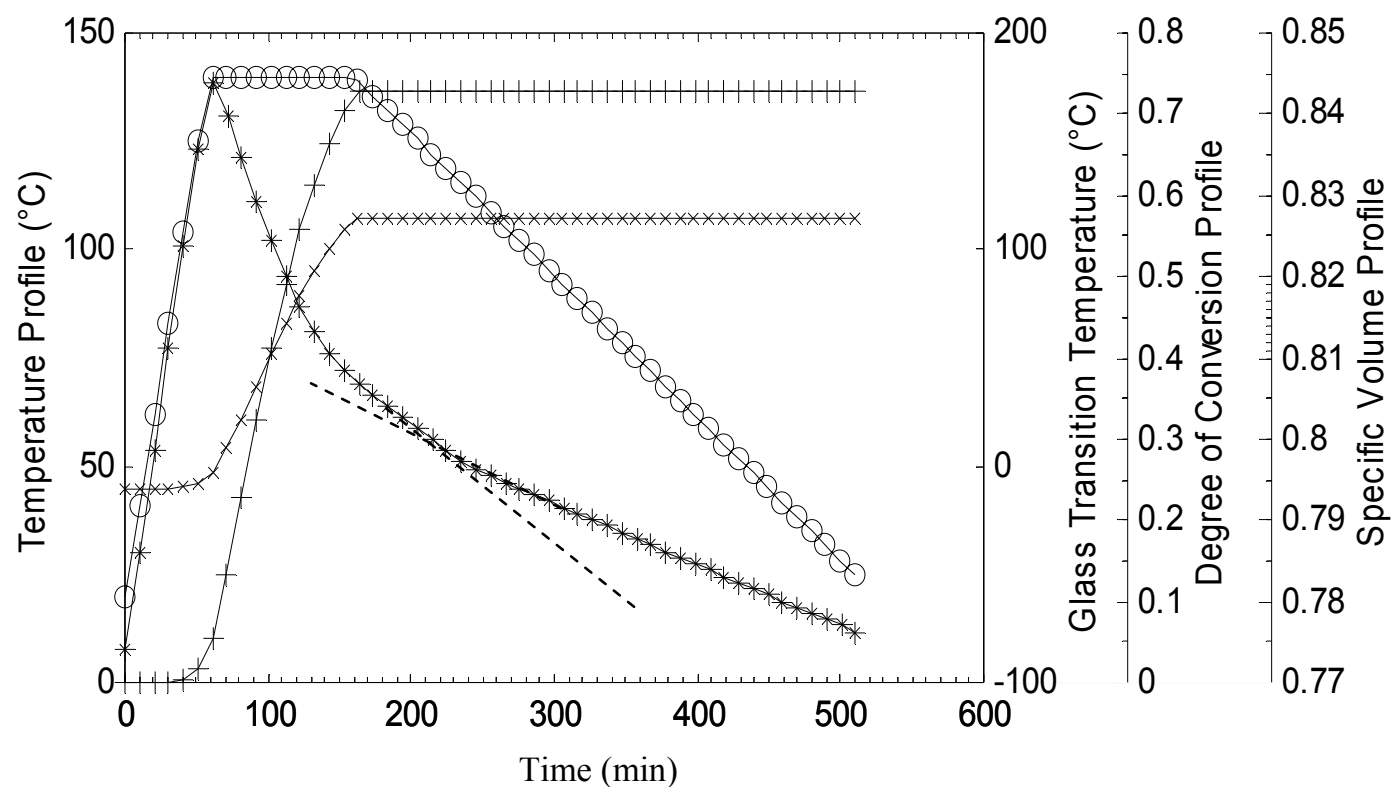

o Temperature

x Glass Transition

+ Conversion

* Specific Volume

(b)

Fig. 11 Predicted property changes during two simulated representative thermal profiles 